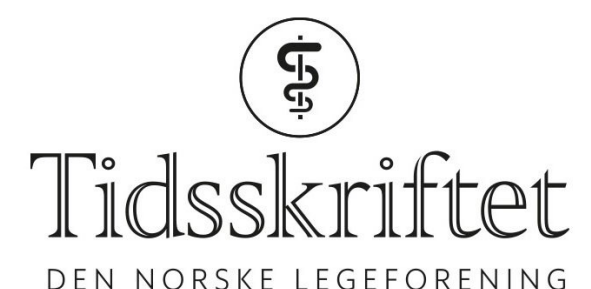

DEN NORSKE LEGEFORENING

\title{
Migrant health is global health
}

GLOBAL HELSE

\section{BERNADETTE N. KUMAR}

E-mail: bernadette.kumar@nakmi.no Bernadette N. Kumar (born 1965), MD, PhD, Director, Norwegian Centre for Migration and Minority Health (NAKMI); Associate Professor, HELSAM, University of Oslo; Commissioner Lancet Commission Migration and Health.

The author has completed the ICMJE form and reports no conflicts of interest.

\section{HARALD SIEM}

Harald Siem (born 1941), MD, Dr. med, MPH, Senior Adviser, Norwegian Centre for Migration and Minority Health; former Director Medical Services, International Organization for Migration. The author has completed the ICMJE form and reports no conflicts of interest.

\section{INGEBORG HAAVARDSSON}

Ingeborg Haavardsson (born 1967), MSc, Coordinator, Centre for Global Health, University of Oslo. The author has completed the ICMJE form and reports no conflicts of interest.

\section{ANDREA SYLVIA WINKLER}

Andrea Sylvia Winkler (born 1966), MD, PhD, Professor, Department of Community Medicine and Global Health; Director, Centre for Global Health, University of Oslo; Specialist Neurologist and Senior Researcher, Centre for Global Health, Department of Neurology, Technical University of Munich.

The author has completed the ICMJE form and reports no conflicts of interest.

The number of migrants worldwide is at a record high level. An investment in migrant health is an investment in the future: migrants should be seen as a resource rather than a burden.

The 'Migration Period' of the Middle Ages (300-700 AD) resulted in dramatic changes in the architecture of populations in Europe. Many would argue that we are currently in the midst of a similar 'Migration Period' $(1,2)$. The 2015 refugee crisis might seem to some like an overwhelming tidal wave of humans. While the term 'migrant' is often used in communicating to a broad audience, the complexities of the many subgroups under this terminology are often lost. Refugees are a subset of the broader category of migrants. The United Nations High Commissioner for Refugees (UNHCR) reports 67.7 million people of concern worldwide (refugees, asylum seekers, internally displaced persons and stateless persons) of which more than 17 million are refugees (3). In Europe, Eastern Europe has the largest proportion people of concern (6.2 million) compared to the rest of Europe (3.9 million), with over $50 \%$ of those being internally displaced persons (3). Europe's proportion of refugees ( 5.2 million) is less than 1 per cent of the total European population (3). 
Migration features high on the United Nations (UN) agenda. In 2016, the International Organization for Migration (IOM) became part of the UN system (4), and the UN General Assembly issued the New York Declaration for Refugees and Migrants that expresses the political will of world leaders to save lives, protect rights and share responsibility on a global scale (5). The 15 July 2017 issue of The Economist brought an interesting dimension into the debate about migration: If borders were to open, globally, the world stood to gain. Quote: 'Labour is the world `s most valuable commodity - yet thanks to strict immigration regulation, most of it goes to waste' (6).

Migration research, policy and practice often address demographics, politics, conflicts, labour and education, whereas unfortunately health often falls between the cracks.

\section{Resource for the future}

Investment in health as a means of positive economic growth and development per se improves health. Improved global health is not just an end in itself but a means of achieving other, broader societal goals. The same is true of migrants' health. Migrants should be looked upon as a resource and an investment in the future, not merely as a burden to society. The Public Health Committee of the Council of Europe adopted recommendations on mobility, migration and access to health care in 2011. Some of the guiding principles agreed by the experts were to monitor migrants' health status, provide migrants with adequate entitlements and increase the accessibility of health services (7). WHO has also pursued the agenda and a Strategy and Action Plan for Refugee and Migrant Health in the WHO European Region was adopted in 2016 (8).

The recent WHO European Region report on 'Migration and Health: key issues' takes a sober public health approach to the challenges. It presents the health problems of migrants, including refugees, as being similar to those of the rest of the population, with some differences in the levels of disease prevalence. The evidence presented does not justify the irrational fear of infectious disease, including tuberculosis. The key issue regarding noncommunicable diseases is the interruption of treatment and care, either due to lack of access or the decimation of health care (9). WHO does not recommend mandatory screening of refugee and migrant populations for disease, due to lack of evidence of its benefits; moreover, it can lead to anxiety in individual migrants and the wider community. This does not preclude health checks and access to care for those who require assistance.

\section{Sound policy}

The 2016 Migration Integration Policy Index's (MIPEX) health strand (10) confirmed that policies and practices vary across countries and across groups of migrants. Few countries offer both good quality health services and good access for migrants. The responsiveness of services to migrants' health needs has a long way to go. Measures to achieve change, with a few exceptions, are falling short. The challenges are numerous. How best to receive the newcomers? How to ease their transition from one world to another? How best to integrate them in a culture with widely different values and lifestyles? In light of the widening gaps in inequality, there is an urgent need to prioritise and agree upon a common health agenda (11).

While appropriate structures to address the health issues of migrants must be considered within the national context, global efforts to solve health problems together must not be forgotten. This means that host countries need to look beyond national borders and collect information on disease epidemiology, management, vaccination coverage and the condition of health systems, among others, in the migrants' countries of origin. All of the aforementioned is part of 'classical' global health as alluded to by the Global Health 2035 Lancet Commission (12). Global health is derived from public health and international health which in turn evolved from hygiene and tropical medicine. The history of global health is embedded in a geographic North-South focus that prioritised infectious diseases 
(13).

On arrival, effective, tailor-made health information to enable migrants to access the host country's healthcare system to prevent accidents, injuries and disease in the new environment must be provided. It has been well established that mental health is key to better overall health (14) and therefore needs to be addressed, both in the short and long term. The long-term psychological and economic impacts of conflict and displacement are well documented (15). There is a need for culturally appropriate psychosocial support services. Language barriers and health literacy issues need to be identified and resolved. If successful, this approach represents a long-term investment in global health.

The World Health Organization (WHO) published a report on macroeconomics and health (16) shortly after the turn of the millennium, in which health costs were considered as investments. Investment in health as a means of positive economic growth and development per se also improves health, and this holds true for migrants as well.

\section{Knowledge gap}

Data and information on the health of refugees and migrants, and information and dialogue with the migrants, are crucial to address the health challenges and prioritise interventions. The type of data that should be collected, by whom, at what level and to what purpose needs discussion, consensus and standardisation. Knowing the occurrence of infectious and non-infectious disease in migrant populations, it is necessary to respond appropriately to individual and population needs aligned with global health principles. Reliable knowledge about migrant groups and health is a prerequisite for equal access to prevention and treatment of illness. Equal opportunities for achieving good health should be one of the key priorities of global migrant health.

The following recommendations should be considered. First, researchers and policy makers need to agree on standardised definitions of 'migrants' and acquire complete and reliable data matching those definitions. Second, government and donors need to address information gaps in order to ensure the development of a framework to monitor disease and ill-health among migrant populations. Third, policy makers, researchers and practitioners must prioritise research on medium-/long-term migration health, including longitudinal studies on integration and health, intervention studies documenting what has and has not worked, and global comparative studies evaluating migrant populations in several countries, including countries of origin, must be prioritised.

Driven by global health principles, migrant health requires coordination and collaboration in the health sector and beyond among healthcare providers, public, private and nongovernmental organisations. Besides human rights, legal frameworks and the economic arguments, public opinion and humanitarian aspects must galvanise political action.

It is worth remembering Martin Luther King in an address to the Second National Convention of the Medical Committee of Human Rights in 1966: 'Of all the forms of inequality, injustice in health care is the most shocking and inhumane.' It remains to be seen whether this situation has changed more than 50 years later.

\section{REFERENCES:}

1. Giddens A, Sutton PW. Chapter 16. In: Essential concepts in Sociology. Cambridge: Polity Press, 2017.

2. Martell L. Chapter 5. In: The Sociology of Globalisation. Cambridge: Polity Press, 2010

3. The United Nations High Commissioner for Refugees (UNHCR). Global trends: Forced displacement in 2016.2017.

http://www.unhcr.org/statistics/unhcrstats/5943e8a34/global-trends-forced-displacement-2016.html (20.11.2017).

4. The United Nations General Assembly. Resolution adopted by the General Assembly on 25 July 2016. 
Agreement concerning the Relationship between the United Nations and the International Organization for Migration. 2016.

https://digitallibrary.un.org/record/837208/files/A_RES_70_296-EN.pdf(20.11.2017).

5. United Nations. New York Declaration for refugees and migrants. 2016. https://digitallibrary.un.org/record/844669/files/A_RES_71_1-EN.pdf(20.11.2017)

6. The Economist. If borders were open: A world of free movement would be $\$ 78$ trillion richer. July, 2017.https://www.economist.com/news/world-if/21724907-yes-it-would-be-disruptive-potential-gains-ar e-so-vast-objectors-could-be-bribed (20.11.2017).

7. Nørredam M, Krasnik A. Migrants' access to health services. In: Rechel B, Mladovsky P, Devillé W et al (ed). Migration and health in the European Union. New York: Open University Press, 2011: 71-2.

8. World Health Organization. Strategy and action plan for refugees and migrant health in the WHO European Region. 2016.

http://www.euro.who.int/__data/assets/pdf_file/ooo4/314725/66wdo8e_MigrantHealthStrategyAction Plan_160424.pdf?ua=1(20.11.2017).

9. World Health Organization. Migration and health: key issues. WHO Regional Office for Europe. http://www.euro.who.int/__data/assets/pdf_file/oo05/293270/Migration-Health-Key-Issues-.pd $\mathrm{f} ? \mathrm{ua}=1(20.11 .2017)$

10. MIPEX. Migrant Integration Policy Index 2015.

http://www.mipex.eu/sites/default/files/downloads/pdf/files/custom/a4/2017.11.01-o8.58.o7-mipex-2015custom-book-a4.pdf(20.11.2017).

11. Ingleby D, Chiarenza A, Deville W et al. Inequalities in Health Care for Migrants and Ethnic Minorities. COST Series on Health and Diversity. Antwerpen: Garant Publishers. 2012.

12. Jamison DT, Summers LH, Alleyne G et al. Global health 2035: a world converging within a generation. http://www.globalhealth2035.org/sites/default/files/report/global-health-2035.pdf (20.11.2017).

13. Koplan JP, Bond TC, Merson MH et al. Towards a common definition of global health. Lancet 20o9; 373: 1993 - 5. [PubMed][CrossRef]

14. World Health Organization. Mental Health Action Plan 2013-2020.

http://apps.who.int/iris/bitstream/10665/89966/1/9789241506o21_eng.pdf(20.11.2017).

15. Bhugra D, Gupta S. Migration and mental health. Cambridge: Cambridge University Press, 2011.

16. Sachs JD. Macroeconomics and health: Investing in health for economic development - report of the Commission on Macroeconomics and Health. Geneva: World Health Organization, 2001. http://www1.worldbank.org/publicsector/pe/PEAMMarch2005/CMHReport.pdf(20.11.2017).

Published: 20 December 2017. Tidsskr Nor Legeforen. DOI: 10.4045/tidsskr.17.0656

Received 1.8.2017, first revision submitted 9.10.2017, accepted 20.11.2017.

(C) The Journal of the Norwegian Medical Association 2020. Downloaded from tidsskriftet.no 